\title{
STUDY ON PHYSICO-MORPHOLOGICAL SEMINAL CHARACTERS OF GERMAN SHEPHERD CANINE BREED
}

\author{
K. RAY*, A. K. JHA ${ }^{1}$, P. BISWAS AND S. BASU \\ Department of Veterinary Gynaecology and Obstetrics \\ Faculty of Veterinary and Animal Sciences \\ West Bengal University of Animal and Fishery Sciences \\ 37, K B Sarani, Kolkata -700 037, W. B., India
}

\begin{abstract}
The present study was undertaken with six numbers of German Shepherd dogs from different locations of Belgachia, Kolkata, West Bengal. Semen samples were collected biweekly in the morning (8:00 hr) by massage method aseptically from each dog for six occasions. A total of $\mathbf{3 6}$ ejaculates were collected. After collection, all semen samples were pooled, and all the macroscopic characters and physicomorphological seminal characteristics were evaluated. The volume of semen, $\mathrm{pH}$, sperm concentration, individual motility, live percentage of spermatozoa, positive for hypo-osmotic swelling test( HOST) and total sperm abnormality percentage were $5.516 \pm 0166 \mathrm{cu} \mathrm{mm} ., 6.383 \pm 0.031,274.333 \pm 2.667 \times 10 \% \mathrm{~mL}$, $76.333 \pm 2.728 \%, 84.166 \pm 1.990,80.166 \pm 2.522$ and $14.83 \pm 2.386$, respectively. In the study all the dogs were found fertile.
\end{abstract}

Key words: German Shepherd dog (GSD), Physico-morphological character, Semen

Dog has not only a tremendous mental healing power and guarding ability but also gradually becoming one of the biggest income generating animal. Dog should receive maximum love, affection and more importantly proper health care management and treatment. Attention should also be given for production of optimum quality breed consisting of those characteristics which are essential for fulfilling the human needs.
Semen evaluation and its preservation are the two vital requisite for successful artificial insemination (AI). Use of chilled extended semen for AI in the canine has become increasingly popular over the last 2 decades. Semen parameters such as semen volume, sperm concentration, motility percentage of spermatozoa, percentage of live and dead spermatozoa and sperm morphology in the whole ejaculate are frequently examined to assess the quality of

"Corresponding Author

${ }^{1}$ Regional Agricultural Research Station, Parwanipur, Bara, Nepal 
semen. The functional integrity of the sperm plasma membrane is crucial for the viability and fertilizing ability of spermatozoa (Hafez, 1993). The hypo-osmotic swelling test (HOST) by using distilled water has been effectively used to assess the functional integrity of sperm plasma membrane (Lomeo and Giambersio, 1991).

Spermatozoa must have good motility in order to reach the oviduct and to penetrate the investments around the oocyte. An intact plasmalemma is a prerequisite for maintaining membrane potential, ionic micro environment and $\mathrm{pH}$. Furthermore, spermatozoa cannot survive in the female reproductive tract and bind to the zona pellucida and the vitelline membrane without having an intact plasmalemma. Damage to acrosome can also result in infertile spermatozoa, since acrosomal enzymes are needed for penetration of the zona pellucida and fusion with the oocyte (Bedford, 1970; Roberts, 1986).

To evaluate the fertility of a male dog, several methods have been proposed. Although the evaluation of conception rates remains the ultimate test to assess male fertility, this method is time-consuming and causes birth of unwanted puppies (Oettle, 1993). Therefore, alternative methods to assess the fertilizing capacity of canine spermatozoa in vitro are required and for this reason HOST is performed as in vitro fertility test.

In the present study, an attempt has been made with the canine species of German
Shepherd dog breed. Evaluation of semen characteristics of this breed was taken into consideration.

\section{MATERIALS AND METHODS}

The present study was undertaken in the Department of Gynaecology and Obstetrics, Faculty of Veterinary and Animal Sciences, West Bengal University of Animal and Fishery Sciences, Kolkata. The semen was collected for ten weeks from six German Shepherd dog breeds for study under this experiment. The animals were selected from different locations of Belgachia, Kolkata, West Bengal. The ages of experimental dogs were 3 to 4 years and the body weights were $25 \mathrm{~kg}$ to $32 \mathrm{~kg}$. Soon after selection, a thorough history of those animals was taken. It included injuries, illness, treatments, management practices and owner observations related to development of reproductive problem, behavior and mating experiences. Semen was collected by digital manipulation (Macpherson and Panner, 1967; LindeForsberg, 1991; Kutzler, 2005). Under ideal conditions, this procedure was performed in the presence of an estrous bitch.

The parameters for study with fresh semen were volume, $\mathrm{pH}$, sperm motility, sperm concentration, percentage of live spermatozoa, percentage of different types of abnormalities of head, mid piece and tail, and hypo-osmotic swelling test (HOST). The first (pre-sperm) fraction is small in volume and contains few to no 
spermatozoa. The second (Sperm rich) fraction comes from the epididymes and testes. The third (prostatic) fraction consists solely of prostatic fluid and also contains few to no spermatozoa. The volumes of the first and third fractions, especially the later, are variable, and the volume of the third fraction was controlled by the person during collecting the sample, as they choose to collect more or less of the cell free prostatic fluid. Volume is not an indicator of semen quality in dogs. However the volume measurement is part of the calculation of total number of spermatozoa in the sample, which is one indicator of semen quality. The $\mathrm{pH}$ of dog semen was measured by $\mathrm{pH}$ paper in the $\mathrm{pH}$ range from 5.0-8.0 (Freshman, 2002). The mass activity of the spermatozoa was carried out and gradation was done on the basis of character of waves as expressed by Seager and Platzz (1977) and individual motility was observed followed by grading 0-5 as advocated by Herman and Swanson (1941) and finally expressed as the percentage of total motile or progressively motile spermatozoa. Sperm concentration was determined by haemocytometer technique (Andersen, 1975). Live percentage of spermatozoa was done using eosin-nigrosin stain as described by Andersen (1975). To determine the percentage of different types of abnormalities of head, mid piece and tail, Rose-Bengal stain was used (Castelo et al., 2010). The HOST was done as per Jeyendran et al. (1984) where at least 100 spermatozoa were examined under phase contrast microscope (Olympus Optical Co.,
Tokyo, Japan; CX21i-LED, Binocular Version).

Data was analyzed by the general linear model of the SPSS software version 20 . The means were compared using Duncan's multiple range tests. The probability of $\mathrm{P}<0.05$ was considered to be statistically significant. Correlation was done through Pearson correlation study in SPSS.

\section{RESULTS}

Mean semen volume of German Shepherd dogs was found to be $5.516 \pm 0.116 \mathrm{cu} \mathrm{mm}$. Mean of semen $\mathrm{pH}$ was $6.383 \pm 0.031$. Mean of sperm concentration of German shepherd dogs was $274.333 \pm 2.667 \times 10^{6} /$ $\mathrm{mL}$. Progressive motility of the sperm was estimated as $76.333 \pm 2.728 \%$. Live percentage of spermatozoa was $84.166 \pm$ $1.990 \%$. Mean value of hypo-osmotic swelling test (HOST) was showed 80.166 \pm 2.522. Total sperm abnormality percentage was $14.830 \pm 2.386$.

\section{DISCUSSION}

Despande et al. (1970), reported semen volume of Alsatian and Golden Retriever were $5.9 \mathrm{~mL}$ and $5 \mathrm{~mL}$ respectively, which was similar to our experiment. Correa et al. (1997) also recorded semen volume of breed like Grey Hound was $7.5 \mathrm{~mL}$. Daiwadnya et al. (1995) in their study on evaluation of dog semen reported that, in 48 ejaculates, the average volume was $2.57 \mathrm{~mL}$.

The value of $\mathrm{pH}$ of the present findings was corroborated with the finding of Daiwadnya 
et al. (1995), who reported it as 6.57. The $\mathrm{pH}$ of the second fraction (sperm rich) of domestic canine ejaculates was approximately 6.2 (Rota et al., 1995). In agreement with measured ejaculate $\mathrm{pH}$, Foote and Leonard (1964) found extender at $\mathrm{pH} 6.6$ to be superior to both 5.9 and 7.3 for the maintenance of whole ejaculate canine sperm motility stored at $5^{\circ} \mathrm{C}$. While some investigators have titrated their extenders to a pH of 6.8 (Foote and Leonard, 1964) and 6.7 (Rota et al., 1995, 1999), others have maintained extender at a more neutral pH of 7.0 (Smith and Graham, 1984), 7.1 (Thomas et al., 1993) and 7.4 (Hay et al., 1997). In two studies comparing various extender $\mathrm{pH}$, maximum canine sperm motility was maintained in the range of $\mathrm{pH}$ 7.0-8.5 when held at room temperature or at a $\mathrm{pH}$ of 7.3 when held a $39^{\circ} \mathrm{C}$ (England, 1992). Furthermore, England (1992) determined extender $\mathrm{pH} 7.3$ to be the least deleterious on sperm morphology over time compared to $\mathrm{pH} 3.3$, 5.3 and 9.3, and therefore deemed the best overall extender $\mathrm{pH}$.

The value of sperm concentration in the present study was corroborated with the findings of Hancock and Rowland (1949) who reported average concentration of sperm in 19 ejaculates of dog was 275 million/mL. Harrop (1955) reported less average concentration of spermatozoa (125 million/mL) on 100 ejaculates belonging to several breeds of dogs. Daiwadnya et al. (1995) in their study on evaluation of dog semen reported that in 48 ejaculates, the average sperm concentration was 264 million / mL. On contrary, Rota et al. (1995) found the total number of spermatozoa was 916 million/mL.

As the canine ejaculate consists of three fractions, volume and sperm concentration of the sperm-rich fraction will depend on the amount of prostatic fluid collected. Therefore, the total number of spermatozoa in the ejaculate is one of the parameters indicative of semen quality. Total sperm number in normal ejaculates, which may range from 300 to 2000 million (Johnston et al., 2001), is highly variable between breeds, as sperm production depends on testicular size.

The motility ratings in different breeds varied widely as reported by the different workers. Rota et al. (1995) reported that the average motility of canine semen was 78.6\% and Hendrikse and Antonsse (1984) found average motility was $71.38 \%$. The percentage of total motile spermatozoa in normal canine ejaculates was between $70 \%$ and 90\% (Johnston et al., 2001), although it may be lower after prolonged periods of sexual rest. It has been proposed that fertile dogs should have at least $70 \%$ of total sperm motility (Lentner, 1982).

The percentage of live spermatozoa of the present study was in the agreement of Daiwadnya et al. (1995), who reported that in 48 ejaculates, the average live sperm percentage 82.81. The value of HOST in the present study partially corroborates the findings of the other workers. Rota et al. 
(1995) observed the average value of HOST positive sperm was $93.6 \%$.

Wong and Dhaliwal (1985) and Daiwadnya et al. (1995) found the average percentage of morphologically abnormal spermatozoa as $9 \%$ based on 8 ejaculates and 10.08 from 48 ejaculates respectively which was less than our findings of $14.830 \pm 2.386$. Hendrikse and Antonsse (1984) found, for 2024 ejaculates from dogs aged 1 to 9 years representing 121 breeds, the percentage of abnormal spermatozoa was 14.07 which support our findings. Motility decreased with age, while the proportion of abnormal spermatozoa increased significantly.

The prime necessity for professional dog breeders is to recognize the dog in respect

\section{REFERENCES}

Andersen K, 1975. Insemination with frozen dog semen based on a new insemination technique. Zuchthygiene, 10(1): 1-4

Bedford JM, 1970. Sperm capacitation and fertilization in mammals. Biol Reprod, 2(Suppl): 128-158

Castelo TS, Bezerra FSB, Lima GL, Alves HM, Oliveira IRS et al., 2010. Effect of centrifugation and sugar supplementation on the semen cryopreservation of captive collared peccaries (Tayassu tajacu). Cryobiology, 61: 275-279

Correa JR, Pace MM and Zavos PM, 1997. Relationships among frozen-thawed sperm characteristics accessed via the routine semen analysis, sperm functional tests and fertility of bulls in an artificial insemination program. Theriogenology, 48(5): $721-731$ of its fertility as well as pedigree selection for hybridization practice to maintain the trend of further enhancing the production of good quality puppies. In this context, present findings can help to get much more information on different aspect of semen parameters to encourage the future research on enhancement of quality and preservation process of German Shepherd dog semen.

\section{ACKNOWLEDGEMENT}

Authors would like to acknowledge all the faculty members of the Department of Veterinary Gynecology and Obstetrics, WBUAFS, Kolkata for their valuable suggestion and assistance during experimental period.

Daiwadnya CB, Hukeri VB and Sonawane SA, 1995. Studies on evaluation of dog semen. Livest Adv, 20(11): 34-37

Despande BR, Velhankar DP, Hadi MA, Gujrathi KG, Hukeri VB et al., 1970. Bom Vet Coll Mag XVII: 27

England GCW, 1992. The cryopreservation of canine semen. Thesis, University of London

Foote RH and Leonard EP, 1964. Influence of $\mathrm{pH}$, osmotic pressure, glycine and glycerol on survival of dog sperm in buffered yolk extenders. Cornell Vet, 54: 78-89

Freshman JL, 2002. Semen collection and evaluation. Clinical Tech Small Anim Pract, 17(3): 104-107

Hafez ESE, 1993. Reproduction in farm animals. Semen evaluation, Lea and Febiger, pp 405-423 
Hancock JL and Rollinson DHL, 1949. A seminal defect associated with sterility of Guernsey bulls. Vet Rec, 61: 742-743

Harrop AE, 1955. Some observations on canine semen. Vet Rec, 67: 494

Hay MA, King WA, Gartley CJ, Leibo SP and Goodrowe KL, 1997. Effects of cooling freezing and glycerol on penetration of oocytes by spermatozoa in dogs. J Repord Fertil , 51(suppl): 99-108

Hendrikse J and Antonsse HW,1984. Evaluation of dog sperm. Tijdschr Diergeneeskd, 109: 171-174

Herman HA and Swanson EW, 1941. Variation in dairy bull semen with respect to its use in artificial insemination. Missouri Agric Exp Sta Res Bull, 326: 1-82

Jeyendran RS, Van der Ven HH, Perez-Pelaez M, Crab OBG and Zanevald LJD, 1984. Development of an assay to assess the functional integrity of the human sperm membrane and its relationship to other semen characteristics. J Reprod Fertil, 70: 219-228

Johnston SD, Root Kustritz MV and Olson PNS, 2001. Canine and Feline Therigeonology, WB Saunders Co., Philadelphia, pp287-306

Kutzler MA, 2005. Semen collection in the dog. Theriogenology, 64(3): 747-754

Lentner C, 1982. Statistical significance tests. In: Geigy scientific tables. Basle, Switzerland: Ciba Geigy Ltd, pp192-202

Linde-Forsberg C, 1991. Achieving canine pregnancy by using frozen or chilled extended semen. Vet Clin North Am Small Anim Pract, 21: 467-485

Lomeo AM and Giambersio AM, 1991. Water test: a simple method to assess sperm- membrane integrity. Int Androl, 14: 278282

Macpherson JW and Panner P, 1967. Canine reproduction: I. Reaction of animals to collection of semen and insemination procedures. Can J Comp Med Vet Sci, 31(3): 62-64

Oettle EE, 1993. Sperm morphology and fertility in dog. J Reprod Fertile Suppl, 47: 257-260

Roberts SJ, 1986. Fertilization and transport of the ovum, sperm and zygote. In: Roberts SJ (ed), Veterinary Obstetrics and Genital Diseases (Theriogenology). Woodstock, Vermont, pp422-427

Rota A, Iguer-ouada M, Verstegen J and LindeForsberg C, 1999. Fertility after vaginal or uterine deposition of dog semen frozen in a tris extender, with or without Equex STM paste. Theriogenology, 51: 1045-1058

Rota A, Strom B and Linde-Forsberg C, 1995. Effects of seminal plasma and three extenders on canine semen stored at $4^{\circ} \mathrm{C}$. Theriogenology, 44: 885-900

Seager SW and Platz CC, 1977. Collection and evaluation of canine semen. Vet Clin North Am, 4: 765-773

Smith FO and Graham EF, 1984. Cryopreservation of canine semen: technique and performance. $10^{\text {th }}$ Int Cong Anim Reprod, 2: 216, 944-960

Thomas PGA, Larsen RE, Burns JM and Hahn CNA, 1993. Comparison of three packaging techniques using two extenders for the cryopreservation of canine semen. Theriogenology, 40(6):1199-1205

Wong WT and Dhaliwal GK, 1985. Observations on semen quality of dogs in the tropics. Vet Rec, 116(12): 313-314

Article received on 30.02.2019 and accepted for publication on 21.05.2019 